\title{
Tautomerism of Cytosine on Silver, Gold, and Copper: Raman Spectroscopy and Density Functional Theory Calculation Study
}

\author{
Kwang-Hwi Cho and Sang-Woo Joo ${ }^{\dagger *}$ \\ Department of Bioinformatics and Life Science and CAMDRC and Department of Chemistry, Soongsil Lniversity. \\ Seoul 156-743, Korea. ${ }^{*}$ E-mail: chokhaissu.ac.kr; sjoogissu.ackr \\ Received September 28, 2007
}

\begin{abstract}
Tautomerism of py'rimidine base cytosine has been comparatively examined on nanoparticle and roughened plate surfaces of silver. gold. and copper by surface-enhanced Raman scattering (SERS). The SERS spectrum was found to be different depending on the metals and their substrate conditions suggesting the dissimilar population of various tantomers of cytosine on the surfaces. The $a b$ initio calculations were performed at the levels of B3LYP. HF. and MP2 levels of theory with the LanL2DZ basis set to estimate the energetic stability of the tautomers with the metal complexes as well as the gas phase state. The amino group and $\mathrm{N}_{2}$-coordinated tautomer was predicted to be more favorable for bonding to $\mathrm{Au}$. whereas the hydroxyl and $\mathrm{N}_{1}$-coordinated zwitter ionic form is most stable with $\mathrm{Ag}$ and $\mathrm{Cu}$ as a bidentate form from the DFT calculation. The binding energy with the $\mathrm{Ag}$ atom is calculated to be smaller than those with the $\mathrm{Au}$ and $\mathrm{Cu}$ atoms in line with the temperature-dependent SERS spectra of cỵtosine.
\end{abstract}

Key Words : Cytosine, Tautomerism. Coinage metals, SERS, DFT calculation

\section{Introduction}

There has been increasing interest in estimating the stabilities of various geometric forms of nucleic acid bases due to their potential importance in genetics and related fields. ${ }^{1-4} A b$ initio calculations have been employed to predict the structure and energetics of nucleic acid bases. 5.6 Cytosine. one of the simplest pyrimidine bases. has been a frequent subject of theoretical studies due to its biochemical importances ${ }^{7-9}$ Vibrational spectra of DNA bases are calculated by DFT calculations. ${ }^{\text {lot }}$

Binding properties of cytosine on metal surfaces have been studied by means of various spectroscopic tools. ${ }^{1-16}$ The energetics of cytosine-gold interactions were recently investigated by temperature programmed desorption and reflection absorption FT-IR spectroscopy. . $^{1.12}$ Adsorption of single stranded DNA consisting of cytosine bases was investigated by means of X-ray photoelectron and FT-IR spectroscopy ${ }^{\text {l. }}$ An infrared reflection absorption study of cy'tosine indicates that the molecule is expected to have an upright geometry on $\mathrm{Cu}(110)$ via its $\mathrm{N}_{1}$-coordinating atom with the amino group pendent from the surface. ${ }^{15}$ For $1.5-$ dimethylcytosine. the interaction energy with the metal surface is assumed to grow in the order of $\mathrm{Ag}<\mathrm{Au}<\mathrm{Cu}^{16}$

The optical properties of metal nanoparticles have attracted both scientific and technological interest in the past two decades due to their potential applications in many areas. ${ }^{17.18}$ Surface-enhanced Raman scattering (SERS) on metal surfaces has shown great potential for use in biomedical analysis. ${ }^{15}$ The analysis of spectral features has provided detailed information on surface reactions and the geometry of adsorbates. ${ }^{\text {D2.21 }}$ SERS has recently been used to monitor analy'te-surface binding interactions as biosensors. :-

Numerous cases have been reported indicating that the adsorption behavior depends on the metal substrates. ${ }^{3-29}$ The detailed origins of the different adsorption characteristics on metal substrates have not been fully clarified. however. Tautomeric stabilities appeared to be different depending on metal substrates. Recently we performed an SERS study of uracil and thymine on gold and silver nanoparticles in a comparative way using ab initio methods at B3LYP and MP2 levels of theory. 28.29 The $\mathrm{N}_{3}$-deprotonated tautomer of both uracil and thymine was predicted to be more favorable on $\mathrm{Au}$ than on $\mathrm{Ag}$.

Although adsorption of cytosine has been previously studied. ${ }^{11-16}$ a detailed analy sis depending on its tautomer was not conducted. To aim at understanding tautomerism of the simplest pyrimidine base upon adsorption on the metal surfaces. we studied tautomerism of cytosine on $\mathrm{Ag}$. $\mathrm{Au}$. and Cu by SERS and DFT calculation.

\section{Experimental Section}

Cytosine ( $\geq 99 \%$ ) was purchased from Sigma Aldrich. The citrate stabilized gold and silver sols were synthesized by the recipes in the literature ${ }^{3.1}$ For Ag. $90.0 \mathrm{mg}$ of $\mathrm{AgNO}_{3}$ in 500 $\mathrm{mL}$ of water was brought to boiling. A solution of $1 \%$ sodium citrate $(10 \mathrm{~mL})$ was then added to the $\mathrm{AgNO}_{3}$ solution under vigorous stirring. For $\mathrm{Au} .133 .5 \mathrm{mg}$ of $\mathrm{KAuCl}_{+}$(Aldrich) was initially dissolved in $250 \mathrm{~mL}$ of water. and the solution was brought to boiling. A solution of $1 \%$ sodium citrate $(25 \mathrm{~mL})$ was then added to the $\mathrm{KAuCl}_{+}$ solution under vigorous stirring. and boiling was continued for $c a$. $20 \mathrm{~min}$. The resulting Au solution was stable for several weeks. All the chemicals otherwise specified were reagent grade and triply distilled water. of resistivity greater than $18.0 \mathrm{MW} \mathrm{cm}$. was used in making aqueous solutions. For $\mathrm{Cu}$. the nanoparticle solution was prepared by the 
following recipe. ${ }^{31}$ All the chemicals otherwise specified were reagent grade and triply distilled water, of resistivity greater than $18.0 \mathrm{MW} \mathrm{cm}$. was used in making aqueous solutions. The SERS plate substrates were produced from a metal plate by an oxidation-reduction cycle using a $\mathrm{CH}$ Instrument $700 \mathrm{~A}$ potentiostat or by eroding the $\mathrm{Ag}$ and $\mathrm{Cu}$ plate using a $\mathrm{HNO}_{3}$ solution.

Raman spectra were obtained using a Renishaw Raman confocal system model 1000 spectrometer equipped with an integral microscope (Leica DM LM). ${ }^{32}$ Raman scattering was detected with $180^{\circ}$ geometry using a peltier cooled (-70 $\left.{ }^{\circ} \mathrm{C}\right)$ CCD camera $(400 \times 600$ pixels). An appropriate holographic notch filter was set in the spectrometer. The holographic grating ( 1800 grooves $/ \mathrm{mm}$ ) and the slit allowed the spectral resolution to be $1 \mathrm{~cm}^{-1}$. The $632.8 \mathrm{~nm}$ irradiation from a $35 \mathrm{~mW}$ air-cooled HeNe laser (Melles Griot Model 25 LHP 928) with the plasma line rejection filter was used as the excitation sources for the Raman experiments. Data acquisition time used in the Raman measurements was approximately $30 \mathrm{~s}$. The Raman band of a silicon wafer at $520 \mathrm{~cm}^{-1}$ was used to calibrate the spectrometer. Temperature dependent Raman measurement could be performed using a Linkan THMS 600 thermal heating stage. ${ }^{3 \hat{y}}$ Since the same excitation wavelength at $632.8 \mathrm{~nm}$ was employed in obtaining all the $\mathrm{Ag}$. $\mathrm{Au}$. and $\mathrm{Cu}$ SERS spectra. the instrumental effect or laser mode should be.

\section{Calculation Methods}

All $a b$ initio molecular orbital calculations were carried out using the Gaussian 03 package ${ }^{\hat{\jmath}}$ The geometry optimization of cytosine and $\mathrm{Ag} / \mathrm{Au} / \mathrm{Cu}$ complex were carried out at the levels of MP2. HF. and B3LYP. The LanL2DZ basis sets with a relativistic effective core potential have been used for $\mathrm{Ag}$. Au. and $\mathrm{Cu}$. The six tautomeric forms that could be coordinated to metal atoms were considered among many possibilities. ${ }^{7}$ The geometry optimization for the tautomers was carried out starting from many possible orientations. During the geometry optimization. no geometric constraints such as planarity were used for the present calculation.

\section{Results and Discussion}

Raman Spectra. Figure 1 shows the ordinary Raman (OR) spectrum of cytosine in neat solid state the Ag. Au. and Cu SERS spectra at high bulk concentration of $\sim 10^{-3} \mathrm{M}$. It seemed a rather straightforward to correlate the $O R$ bands with the SERS bands. Their peak positions are listed in Table 1 along with the appropriate vibrational assignments. Our assignment is mainly based on the previous literatures. ${ }^{\text {je }}$ The concentration of cytosine in the aqueous solution was $\sim 10^{-3} \mathrm{M}$. This concentration should correspond to cytosine on metal surface at the concentration above a full-coterage limit by assuming that the adsorbate was oriented perpendicularly with respect to the colloidal surfaces. ${ }^{2 \leqslant-59}$ Our spectrum on $\mathrm{Ag}$ appeared to be consistent with this report. ${ }^{11}$

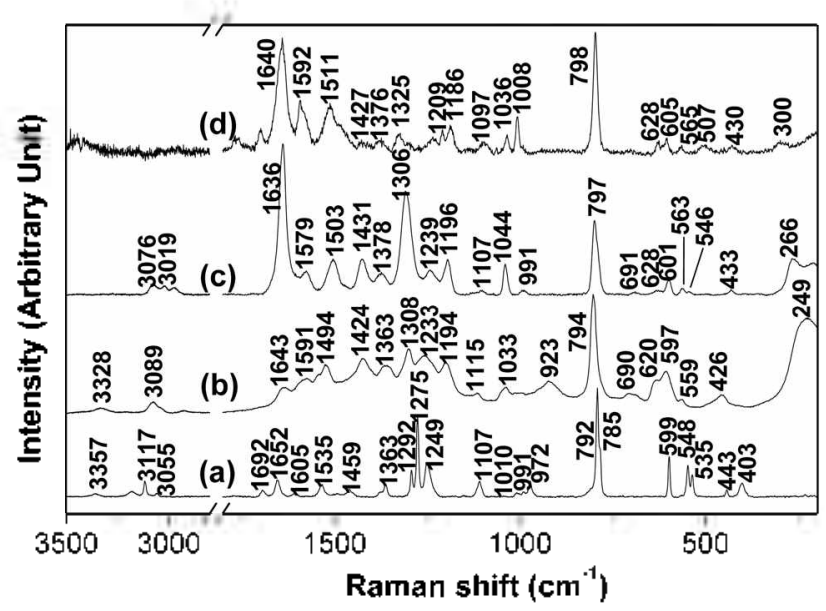

Figure 1. (a) OR spectrum of cytosine in neat solid state and SERS spectra in aqueous (b) silver, (c) gold, and (d) copper nanoparticle solutions. All spectra were taken using the He-Ne laser at the 632.8 nm irradiation. The spectral region between 2800 and $1800 \mathrm{~cm}^{-1}$ was omitted due to the lack of any information.

It has been admitted that the colloidal conditions for Ag. Aul. and $\mathrm{Cu}$ nanoparticle solutions may be not be adequate to discuss the tautomerism of cytosine. For instance it seems difficult to discuss the stability of the zivitter ionic conformers in aqueous solutions without considering the solvation effect. To compare better the differences in the SERS spectra. we have obtained the SERS spectra on $\mathrm{Ag}$. Au. and Cu plates after drying the solution as listed in Figure 2. Their peak positions are also listed in Table 1 . It was found that the SERS spectra on the plates appeared to be somewhat different from those on the nanoparticles. indicating that the stability of the tautomers could change depending on the medium conditions.

Regarding the adsorbate orientation on the surfaces, as shown in Figure 1, it is noteworthy that the ring $\mathrm{C}-\mathrm{H}$ stretching bands were identified at $\sim 3060 \mathrm{~cm}^{-1}$, albeit weakly. in the Ag. Au. and Cu SERS spectra. It has been well documented in the literature that the presence of the ring $C$ $\mathrm{H}$ stretching band in an SERS spectrum is indicative of a vertical (or at least tilted) orientation of the aromatic ring moiety on a metal substrate.

The ring breathing mode in the OR spectrum exhibited neither a substantial red shift nor the increase of its bandwidth as in the $\mathrm{Ag}$. $\mathrm{Au}$, and $\mathrm{Cu}$ SERS spectra shown in Figures 1 and 2. The blue slift of the ring breathing mode may indicate a rather weak interaction of the aromatic rings on the gold and silver surfaces. Neither a substantial red shift nor a significant band broadening of the ring breathing modes was observed for the case of cytosine on Ag. Au. and $\mathrm{Cu}$ where the molecule is assumed to have a standing orientation. 2 , 29

Since an unequivocal selection rule is not available for SERS, the exact tilt angle canuot be detemined for cy tosine at present. According to the electromagnetic (EM) theory on the SERS selection rule. ${ }^{19}$ vibrations along the direction perpendicular to the surface are expected to be more 
Table 1. Spectral Data and Vibrational Assignment of Cytosine on Ag, Au, and Cu Surfaces"

\begin{tabular}{|c|c|c|c|c|c|c|c|}
\hline \multirow{2}{*}{$\mathrm{OR}$} & \multicolumn{3}{|c|}{ Sol SERS } & \multicolumn{3}{|c|}{ Plate SERS } & \multirow{2}{*}{ Assignment ${ }^{\text {b.e }}$} \\
\hline & $\mathrm{Ag}$ & Au & $\mathrm{Cu}$ & $\mathrm{Ag}$ & $\mathrm{Au}$ & $\mathrm{Cu}$ & \\
\hline & 249 & 266 & 300 & 230 & 234 & & stretch metal-N \\
\hline 403 & & & & & & & asym bend $C_{2}-0, C_{4}-\mathrm{NH}_{2}(\mathrm{i} . \mathrm{p})$ \\
\hline $4+3$ & 426 & 433 & 430 & 472 & $4 \hat{3} 1$ & 421 & asym. wag $\mathrm{C}_{0}-\mathrm{H}, \mathrm{N}_{8}-\mathrm{H}_{10}(o, p)$ \\
\hline 535 & & 546 & 507 & & & & sym. bend $C_{2}-O, C_{4}-N_{2}$ (i.p.) \\
\hline 548 & 559 & 563 & 565 & 539 & 564 & 570 & def. ring ( $s q \mathrm{z}$ group, $\mathrm{N}_{3}-\mathrm{C}_{4}-\mathrm{C}_{3}$ ) (i.p.) \\
\hline \multirow[t]{2}{*}{599} & 597 & 601 & 605 & & 601 & 607 & def ring (s $\mathrm{g} z$ group, $\left.\mathrm{C}_{2}-\mathrm{N}_{3}-\mathrm{C}_{4}\right)(\mathrm{i}$. p.) \\
\hline & 620 & 628 & 628 & 632 & 689 & 674 & $\mathrm{wag} \mathrm{N}_{8}-\mathrm{H}$ (o.p.) \\
\hline 785 & & & & & & & ring breathing (i.p.) \\
\hline \multirow[t]{2}{*}{792} & 794 & 797 & 798 & 795 & 796 & 802 & ring breathing (i.p.) \\
\hline & 923 & & & & & & asym. wag $C_{s}-\mathrm{H}, \mathrm{C}_{5-\mathrm{H}} \mathrm{H}(\mathrm{o}, \mathrm{p})$ \\
\hline \multirow[t]{2}{*}{972} & & 991 & 1008 & & 962 & & def ring ( $s q z$ group, $N_{1}-C_{s}-C_{3}$ ) (i.p.) \\
\hline & $10 \hat{3} \hat{3}$ & 1044 & 1036 & 1037 & 1038 & 1042 & sym. bend $\mathrm{N}_{8}-\mathrm{H}_{9}, \mathrm{~N}_{8}-\mathrm{H}_{10}(\mathrm{i} . \mathrm{p})$. \\
\hline \multirow[t]{2}{*}{1107} & 1115 & 1107 & 1097 & & & 1122 & asym. bend $N_{1}-H, C_{s}-H$ (i.p.) \\
\hline & 1194 & 1196 & 1186 & 1194 & 1197 & & def. ring (str $N_{1}-C_{2}, C_{2}-N_{3}$ ) (i.p.) \\
\hline 1249 & 1233 & 1239 & 12.35 & 1245 & $124 \hat{3}$ & 1225 & bend all $\mathrm{H}$ (i.p.) \\
\hline 1275 & & & & & & & bend all $\mathrm{H}$ (i.p.) \\
\hline 1292 & 1299 & 1306 & & 1308 & 1306 & 1308 & bend all $\mathrm{H}$ (i.p.) \\
\hline \multirow[t]{2}{*}{1363} & 1363 & 1378 & 1376 & 1360 & 1366 & 1372 & sym bend $\mathrm{N}_{1}-\mathrm{H}, \mathrm{C}_{5}-\mathrm{H}, \mathrm{C}_{-}-\mathrm{H}(\mathrm{i}, \mathrm{p})$. \\
\hline & 1424 & $14 \hat{3} 1$ & 1427 & 1421 & 1429 & & def. ring (str $N_{1}-C_{t}, N_{3}-C_{1}$ ) (i.p.) \\
\hline \multirow[t]{2}{*}{1459} & & & & 1488 & & & sciss. $\mathrm{NH}_{2}$, str. $\mathrm{C}_{4}-\mathrm{NH}_{2}$ (i.p.) \\
\hline & 1494 & 1503 & 1511 & 1527 & 1502 & 1557 & def ring ( $s t r C_{4}-C_{4}$ ), bend all $\mathrm{H}$ (i.p.) \\
\hline 1605 & 1574 & 1579 & 1592 & 1600 & 1600 & 1596 & def ring (str $\left.\mathrm{C}_{4}-\mathrm{C}_{6}\right)$, sciss. $\mathrm{NH}_{2}$ (i.p.) \\
\hline 1652 & 1643 & 1636 & 1640 & 1634 & 1639 & 1651 & def ring (str $\mathrm{C}_{1}-\mathrm{C}_{4}$ ), sciss. $\mathrm{NH}_{2}$ (i.p) \\
\hline 3055 & & 3019 & & & & & asym. str $\left(\mathrm{C}_{s} \mathrm{H}, \mathrm{C}_{\hat{N}} \mathrm{H}\right)(\mathrm{i} . \mathrm{p})$. \\
\hline 3117 & 3089 & 3076 & & 3080 & 3084 & 3089 & sym. str $\left(\mathrm{C}_{4} \mathrm{H}, \mathrm{C}_{\mathrm{r}} \mathrm{H}\right)(\mathrm{i} . \mathrm{p})$. \\
\hline 3357 & 3328 & & & 3328 & & & sym. str $\mathrm{N}_{8}-\mathrm{H}_{4}, \mathrm{~N}_{\varepsilon}-\mathrm{H}_{10}$ \\
\hline
\end{tabular}

"Spectral positions are from Figure 1 and 2. Unit in $\mathrm{cm}^{-1}$. "Based on ref. 10. "Out-of-plane. "In-Plane.

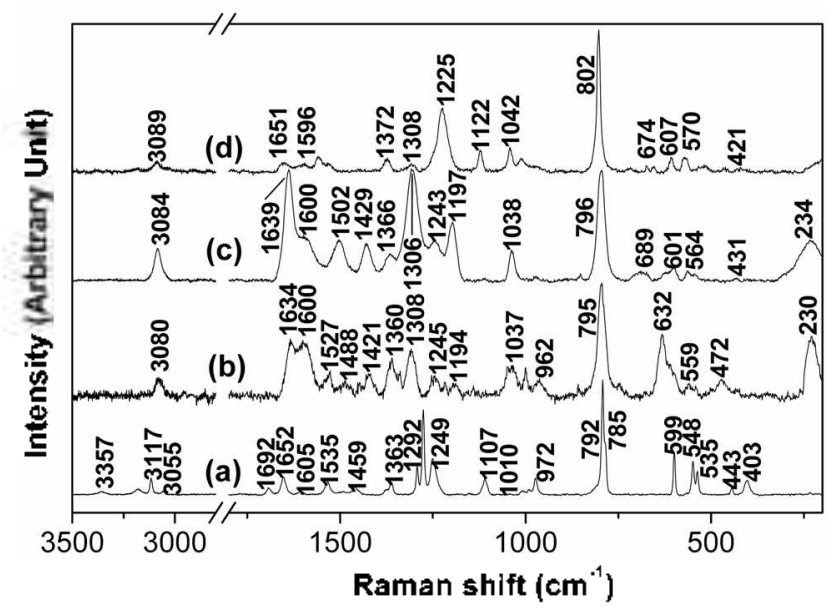

Figure 2. (a) OR spectrum of cy tosine in neat solid state and SERS spectra in (b) silver, (c) gold, and (d) copper plates. All spectra were taken using the He-Ne laser at the $632.8 \mathrm{~mm}$ irradiation. The spectral region between 2800 and $1800 \mathrm{~cm}^{-l}$ was omitted due to the lack of any infonmation.

enhanced than vibrations in the parallel direction. This rule suggested that the in-plane vibration modes should be more enlanced than the out-of-plane ones. The relative intensities have been evaluated for several vibrational modes of cytosine as summarized in Table 2. For cytosine, most ring modes were found to ascribe to the in-plane mode except the weak mode at $\sim 430 \mathrm{~cm}^{-1}$.

It was reported that the charge transfer (CT) mechanism could also significantly contribute the enhancement of the SERS intensities. ${ }^{21)}$ Although the SERS spectra feature could be roughly described by the electromagnetic (EM) mechanism. it is admitted that the CT mechanism may also contribute the SERS intensities of several vibrational bands of cytosine on $\mathrm{Cu}$. Ag. and $\mathrm{Au}$. In fact the different enhancement values for the same symmetry as listed in Table 2 could be better explained with a combination of the EM and CT mechanisms.

Although the band positions and intensities spectra looked somewhat comparable. the SERS spectra showed more complicated features between 1700 and $900 \mathrm{~cm}^{-1}$ indicating the existence of different tautomers of cytosine depending on metal substrates. The difference in the SERS spectral bands may result from the dissimilar population of the tautomers $^{x, 2, s}$ of cytosine upon adsorption on $\mathrm{Ag}$. Au. and Cu.

Also the enhancement factors are observed to be different for sols and roughened surfaces as compared in Table 2. Although most spectral features are analogous with those in the colloidal solutions. several vibrational bands showed 
Table 2. Relative Enhancement Factors of SERS Bands in Cytosine Ring Modes

\begin{tabular}{|c|c|c|c|c|c|c|c|}
\hline \multirow{3}{*}{$\begin{array}{l}\text { Symm- } \\
\text { etry }^{a b}\end{array}$} & \multirow{3}{*}{ Vibrational Modec } & \multicolumn{6}{|c|}{ Enhancement 5 actor $^{d}$} \\
\hline & & \multicolumn{3}{|c|}{ Sol } & \multicolumn{3}{|c|}{ Plate } \\
\hline & & $\mathrm{Ag}$ & Aul & $\mathrm{Cu}$ & $\mathrm{Ag}$ & $\mathrm{Au}$ & $\mathrm{Cu}$ \\
\hline \multicolumn{8}{|c|}{ In-Plane } \\
\hline$A_{1}$ & sym. bend $\mathrm{C}_{2}-\mathrm{O}, \mathrm{C}_{4}-\mathrm{NH}_{2}\left(\sim 530 \mathrm{~cm}^{-1}\right)$ & & .481 & .599 & & & \\
\hline$\alpha_{x x}$ & def. ring $\left(\mathrm{N}_{3}-\mathrm{C}_{+}-\mathrm{C}_{5}\right)\left(\sim 560 \mathrm{~cm}^{-1}\right)$ & .397 & .558 & .380 & .0669 & .0492 & .0897 \\
\hline$a_{y y}$ & def. ring $\left(\mathrm{C}_{2}-\mathrm{N}_{2}-\mathrm{C}_{4}\right)\left(-600 \mathrm{~cm}^{-1}\right)$ & 1.85 & 1.24 & 0.520 & & .0509 & .0758 \\
\hline \multirow[t]{13}{*}{$\alpha_{z 2}$} & ring breathing $\left(-790 \mathrm{~cm}^{-1}\right)$ & 2.27 & 2.40 & 1.35 & .153 & .146 & .244 \\
\hline & def. ring $\left(\mathrm{N}_{1}-\mathrm{C}_{5}-\mathrm{C}_{\mathrm{s}}\right)\left(\sim 970 \mathrm{~cm}^{-1}\right)$ & & 1.11 & 2.84 & & .170 & .562 \\
\hline & asym. bend $\mathrm{N}_{1}-\mathrm{H}, \mathrm{C}_{5}-\mathrm{H}\left(\sim 1100 \mathrm{~cm}^{-1}\right)$ & 1.00 & 1.00 & 1.00 & 1.00 & 1.00 & 1.00 \\
\hline & bend all $\mathrm{H}\left(\sim 1240 \mathrm{~cm}^{-1}\right)$ & 1.19 & 1.15 & & .0839 & .156 & .323 \\
\hline & bend all $\mathrm{H}\left(\sim 1290 \mathrm{~cm}^{-1}\right)$ & & 8.98 & & .267 & .561 & .0604 \\
\hline & sym. bend $\mathrm{N}_{1}-\mathrm{H}, \mathrm{C}_{5}-\mathrm{H}\left(\sim 1370 \mathrm{~cm}^{-1}\right)$ & 2.30 & 3.79 & 1.43 & 468 & .206 & .193 \\
\hline & def. ring (str $\left.C_{4}-C_{5}\right)\left(\sim 1540 \mathrm{~cm}^{-1}\right)$ & 25.7 & 19.2 & & .283 & .414 & .204 \\
\hline & def. ring $\left(\operatorname{str} \mathrm{C}_{5}-\mathrm{C}_{6}\right)\left(\sim 1600 \mathrm{~cm}^{-1}\right)$ & 25.7 & 19.2 & & 2.15 & 1.28 & .517 \\
\hline & sciss. $\mathrm{NH}_{2}($ i.p. $)\left(\sim 1640 \mathrm{~cm}^{-1}\right)$ & 4.30 & 31.9 & 8.28 & .549 & .980 & .115 \\
\hline & asym. str $\left(\mathrm{C}_{5} \mathrm{H}, \mathrm{C}_{6} \mathrm{H}\right)\left(-3040 \mathrm{~cm}^{-1}\right)$ & & 8.35 & & & & \\
\hline & asym. str $\left(\mathrm{C}_{5} \mathrm{H}, \mathrm{C} 6 \mathrm{H}\right)\left(-3080 \mathrm{~cm}^{-1}\right)$ & 1.67 & 2.42 & & .177 & .317 & .128 \\
\hline & sym. str $\mathrm{N}_{8}-\mathrm{H}_{0}, \mathrm{~N}_{8}-\mathrm{H}_{10}\left(-3340 \mathrm{~cm}^{-1}\right)$ & 2.51 & & & & & \\
\hline & Out-of-plane & & & & & & \\
\hline$A_{2}$ & torsion, asym. wag $\mathrm{C}_{6}-\mathrm{H}\left(-430 \mathrm{~cm}^{-1}\right)^{e}$ & 1.88 & 6.53 & 1.49 & 410 & .0876 & .135 \\
\hline$a_{x y}$ & & & & & & & \\
\hline
\end{tabular}

"Svmmetry tyes corresponding to the $C$. point group and numbers in atoms based on " 2 " tautomer. "Subscripts. i.e., $x$, $y$ and $z$. correspond to the confentional molecular axes. 'Based on ref. 9,10 . "Relative Intensity of each ribrational band ( $I_{S E R} I_{\text {GR }}$ ) and nomalized with respect to the vibrational bands at $-1100 \mathrm{~cm}^{-1}$. Number in the parenthesis designates the frequency position in Table 1 and Figures 1 and 2.

different intensities presumably due to the dissinilar medium effects. Since the basicities of the nitrogen and oxygen atoms are different, the most stable tautomer should not be the same depending on the colloidal conditions.

For the SERS spectra on the plates, one of the most noteworthy differences in the All SERS spectrum is a relative increase of the vibrational band at $\sim 1640 \mathrm{~cm}^{-1}$ which could be ascribed to the $\mathrm{NH}_{2}$ scissoring band. This band is found to be much weaker in Ag and Cu SERS spectra (In fact this band is quite strong on $\mathrm{Cu}$ nanoparticle solutions but greatly reduced on $\mathrm{Cu}$ plates). This result suggests that the amino group of cytosine should insolve in bonding to $\mathrm{Au}$ for the dry plate condition in an effective way differently from the cases on $\mathrm{Ag}$ and $\mathrm{Cu}$.

DFT Calculation Results of $\mathrm{Ag}, \mathrm{Au}$, and Cu Metal Complexes with Tautomers of Cytosine. To check our spectral behaviors $a b$ initio calculations were perfomed for the gas phase cytosine of the possible six tautomers labeled to " $1 " \sim 6 "$ as illustrated in Figure 3 and Table 3. Our notation is based on the literature from reference. ${ }^{7,34}$ The " 2 " tautomer was found to be most stable in their gas phase at the level of B3LYP. whereas the " 1 " tautomer appeared to be more stable than the " 2 " tautomer by only 1.7 and $2.1 \mathrm{kcal}$ mol at the level of HF and MP2. respectively. The zwitter ionic " 4 " tautomer was calculated to be least stable for the gas phase presumably due to its charge repulsion as listed in Table 3 .

Upon adsorption on the $\mathrm{Ag}$. $\mathrm{Al}$. and $\mathrm{Cu}$ atom, the available $\mathrm{N}_{3}, \mathrm{~N}_{1}$, or anino group sites of the six tautomers of<smiles>COC1=NC(C)C(C)C(N(C)P)=N1</smiles><smiles>Cc1c(N(C)C)nc(=O)n(N)c1C</smiles><smiles>Cc1nc(=O)n(C)c(N(C)C)c1C</smiles><smiles>Cc1nc(O)nc([N+](C)(C)C)c1C</smiles><smiles>CN=c1nc(OC)n(C)c(C)c1C</smiles>

5<smiles>CN=c1c(C)c(C)nc(OC)n1C</smiles>

6
Figure 3. Tautomers of cytosine considered in this study.

cytosine was considered to check the stabilities. The geometry optimization for the tautomers of cytosine-metal complexes was carried out at the B3LYP/LanL2DZ level of theory starting from many possible structures. The geometry optinizations were converged to one structure for each tautomer even though they were started from many possible configurations. Plausible structures of Ag-cytosine. Aucỵtosine and Cu-cytosine for the amino group and $\mathrm{N}_{3}$ - 
Table 3. Stabilities of the Cy tosine Tautomers in the Gas Phase

\begin{tabular}{cccc}
\hline \multirow{2}{*}{ Tautomer } & \multicolumn{3}{c}{ Total Energy $^{a}$ and Relative Energ. } \\
\cline { 2 - 4 } & B3LYP & HF & MP2 \\
\hline 1 & $-394.8578(6.3)$ & $-392.6338(0.0)$ & $-392.6296(0.0)$ \\
2 & $-394.8678(0.0)$ & $-392.6311(1.7)$ & $-392.6263(2.1)$ \\
3 & $-394.8562(7.2)$ & $-392.6196(8.9)$ & $-392.6153(9.0)$ \\
4 & $-394.7807(54.6)$ & $-392.5363(61.2)$ & $-392.5307(62.1)$ \\
5 & $-394.8219(28.8)$ & $-392.5953(24.1)$ & $-392.3895(25.2)$ \\
6 & $-394.8367(19.5)$ & $-392.6110(14.3)$ & $-392.6059(14.9)$ \\
\hline
\end{tabular}

"Unit: hartree. 1 hartree is $627.51 \mathrm{kcal}$ mol. "Values in parentheses are Energy differences (in kcal.mol) from the most stable confonner for each levels of theory<smiles></smiles>

(a)

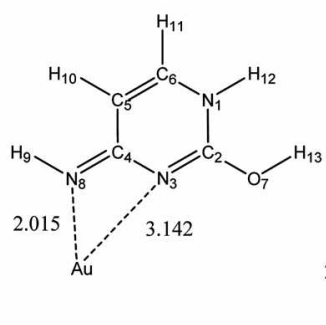

(b)

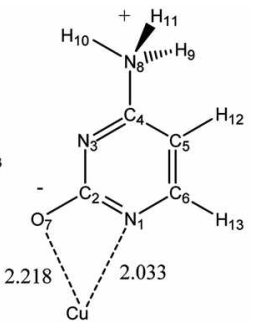

(c)
Figure 4 . The plausibly most stable structures of cy tosine with (a) $\mathrm{Ag}$, (b) $\mathrm{Au}$, and (c) Cu atom. coordinated or $\mathrm{N}_{1}$-coordinated tautomers are drawn in Figure 4 with their optimized geometric variables. The calculated energy values are summarized in Table 4.

In the previous SERS study of 1,5-dimetlyylcytosine, the binding energy via the $\mathrm{N}_{3}$ atom with the metals is estimated to be in the order of $\mathrm{Cu}>\mathrm{Au}>\mathrm{Ag} .{ }^{15}$ As listed in Table 4, the binding energies of $\mathrm{Ag}$ for the $\mathrm{N}_{3}$-coordinated tautomer are calculated to be smaller than those of $\mathrm{Cu}$ and $\mathrm{Au}$ in line with the previous experiments on 1,5-dimethylcy tosine. ${ }^{16}$

It is noteworthy that the $\mathrm{N}_{3}$-coordinated site for the " 5 " tautomer was calculated to be most stable on Au. whereas the $\mathrm{N}_{3}$-coordinated site of the zwitter ionic " 4 " tautomer appeared to be most favorable on $\mathrm{Cu}$ and $\mathrm{Ag}$. Our results suggest that the $\mathrm{N}_{3}$-coordinated tautomer could exist on $\mathrm{Au}$ as evidenced in Raman spectra of Figures 1 and 2. Also it has to be mentioned that the metal can coordinate to cy tosine as a bindentate fashion through the nitrogen atom of pyrimidine and the nitrogen or oxygen atom from the amino or hydroxyl group, respectively. Our calculations indicated that the amino group and $\mathrm{N}_{3}$-coordinated tautomer appeared to be favored on $\mathrm{Au}$ than on $\mathrm{Cu}$ and $\mathrm{Ag}$. Invoking that $\mathrm{Cu}$ and $\mathrm{Ag}$ are more easily oxidized than $\mathrm{Au}$. it is expected that the oxygen atom would have a tendency to get close to $\mathrm{Cu}$ and $\mathrm{Ag}$ than to Au.

Table 4. Stabilities of the $\mathrm{N}_{3}$ - and $\mathrm{N}_{1}$-coordinated Cytosine Tautomer Complexes with Ag, Au, and Cu Atoms from the DFT Calculation ${ }^{\sigma}$

\begin{tabular}{|c|c|c|c|c|c|}
\hline Tautomer & Coordination & $\mathrm{A}:(\mathrm{Cy} t-\mathrm{M})$ & B:(Cyt $(\mathrm{G})-\mathrm{M})$ & C:(Cyt-M(G)) & $\mathrm{BE}_{\mathrm{A}-(\mathrm{B}-\mathrm{C})}{ }^{b}$ \\
\hline & & & $\mathrm{Ag}$ & & \\
\hline 1 & NI & -540.3112 & -145.4741 & -394.7584 & $-0.0787(-49.4)$ \\
\hline 1 & N3 & -540.3265 & -145.4741 & -394.7593 & $-0.0931(-58.4)$ \\
\hline 2 & N3 & -540.3516 & -145.4741 & -394.7673 & $-0.1102(-69.1)$ \\
\hline 3 & NI & -540.3456 & -145.4741 & -394.7563 & $-0.1152(-72.3)$ \\
\hline 4 & NI & -540.2880 & -145.4741 & -394.6821 & $-0.1318(-82.7)$ \\
\hline 4 & N3 & -540.2715 & -145.4740 & -394.6805 & $-0.1170(-73.4)$ \\
\hline 5 & N3 & -540.3225 & -145.4740 & -394.7235 & $-0.1250(-78.4)$ \\
\hline 6 & NI & -540.2822 & $\begin{array}{l}-145.4741 \\
\mathrm{All}\end{array}$ & -394.7374 & $-0.0707(-44.3)$ \\
\hline 1 & NI & -529.9745 & -135.0939 & -394.7565 & $-0.1242(-77.9)$ \\
\hline 1 & N3 & -529.9821 & -135.0939 & -394.7580 & $-0.1302(-81.7)$ \\
\hline 2 & $\mathrm{~N} 3$ & -530.0037 & -135.0939 & -394.7671 & $-0.1426(-89.5)$ \\
\hline 3 & NI & -530.0004 & -135.0939 & -394.7563 & $-0.1502(-94.2)$ \\
\hline 4 & NI & -529.9417 & -135.0939 & -394.6825 & $-0.1653(-103.7)$ \\
\hline 4 & N3 & -529.9129 & -135.0939 & -394.6801 & $-0.1389(-87.2)$ \\
\hline 5 & N3 & -529.9855 & -135.0938 & -394.7215 & $-0.1702(-106.8)$ \\
\hline 6 & NI & -529.9434 & $\begin{array}{l}-135.0939 \\
\mathrm{Cu}\end{array}$ & -394.7355 & $-0.1140(-71.6)$ \\
\hline 1 & NI & -590.6931 & -195.8292 & -394.7581 & $-0.1058(-66.4)$ \\
\hline 1 & $\mathrm{~N} 3$ & -590.7066 & -195.8292 & -394.7580 & $-0.1193(-74.9)$ \\
\hline 2 & $\mathrm{~N} 3$ & -590.7335 & -195.8292 & -394.7654 & $-0.1389(-87.2)$ \\
\hline 3 & NI & -590.7264 & -195.8292 & -394.7553 & $-0.1419(-89.0)$ \\
\hline 4 & NI & -590.6700 & -195.8292 & -394.6805 & $-0.1603(-100.6)$ \\
\hline 4 & N3 & -590.6543 & -195.8292 & -394.6796 & $-0.1455(-91.3)$ \\
\hline 5 & N3 & -590.7058 & -195.8292 & -394.7231 & $-0.1535(-96.3)$ \\
\hline 6 & NI & -590.6640 & -195.8292 & -394.7370 & $-0.0978(-61.3)$ \\
\hline
\end{tabular}

'B3LYPLLANL2DZ. Abbreriations: Cyt: Crtosine. M: Metal. G: Ghost atom. BE: Binding Energ: The shaded rons are the most stable tantomer for each metal. Zero-point energy and BSSE corrections are considered. ${ }^{\circ}$ Energy unit (a.u. hartree). Number in the parethesis indicates the binding energy in Kcal inol. 


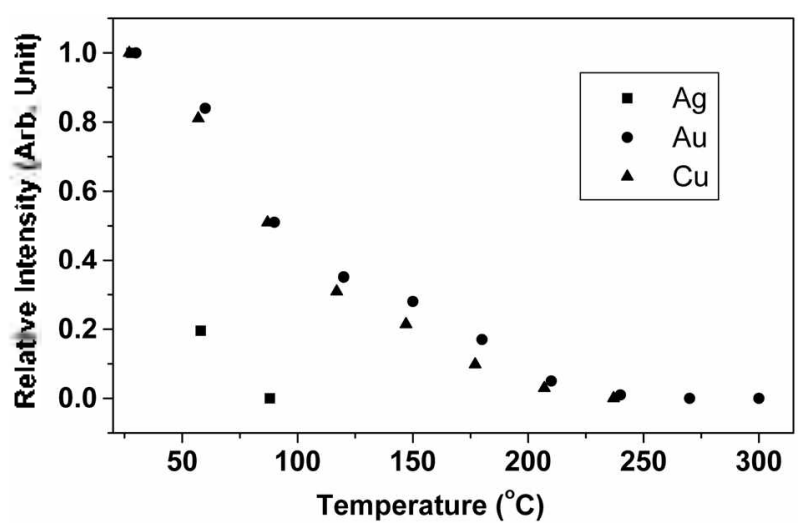

Figure 5. Plot of the intensities of the ring breathing modes at $\sim 790$ $\mathrm{cm}^{-1}$ as a function of temperature on $\mathrm{Ag}(\boldsymbol{\nabla}), \mathrm{Au}(\bullet)$, and $\mathrm{Cu}(\boldsymbol{\Delta})$.

Although the stableness of the amino group and $\mathrm{N}_{3}$ coordinated tautomer on $\mathrm{Au}$ is not well understood. it can cause different spectral features from those on $\mathrm{Cu}$ or $\mathrm{Ag}$ as revealed in Figures $\mathrm{I}$ and 2. Different spectral features on All could be ascribed to the amino group and $\mathrm{N}_{3}$-coordinated tautomer. On the other hand. almost all the SERS bands could be expected to the $\mathrm{N}_{1}$-coordianted tautomer for $\mathrm{Ag}$ and $\mathrm{Cu}$ as referenced from Table 4 .

Our DFT calculations also indicated that the energetic difference of the tautomers should be different depending on the metals. For the most stable tautomer for each metal, the metal- $\mathrm{N}$ bond distance was calculated to be shorter for $\mathrm{Au}$ $(2.015 \AA)$ and $\mathrm{Cu}(2.033 \AA)$ than $\mathrm{Ag}(2.390 \AA)$. This should result in the lower desorption temperature of cytosine on $\mathrm{Ag}$ than on All or Cul.

Figure 5 shows a plot of the intensities of the ring breathing modes at $\sim 790 \mathrm{~cm}^{-1}$ as a function of temperature between 20 and $300^{\circ} \mathrm{C}$. To estimate the SERS intensity changes depending on the temperature. the ring breathing modes at $-790 \mathrm{~cm}^{-1}$ was chosen as a reference. The peak heights of the ring breathing modes at $\sim 790 \mathrm{~cm}^{-1}$ were measured at each temperature. The intensities are normalized with respect to those at room temperature for $\mathrm{Ag}$. Aul and $\mathrm{Cu}$. Decrease in vibrational intensity for the ring breathing modes at $c a .790 \mathrm{~cm}^{-1}$ was measured in increasing temperature. As illustrated in Figure 5, the desorption temperatures of $\mathrm{Au}$ and $\mathrm{Cu}$ appeared to be about the same. whereas that on $\mathrm{Ag}$ was found to be much lower. This result indicates that the binding energy of cytosine on Ag should be smaller than those on $\mathrm{Au}$ and $\mathrm{Cu}$ as in line with the calculated energies in Table 4. The largest binding energies of $\mathrm{Ag}$. $\mathrm{Al}$. and $\mathrm{Cu}$ atoms among various tautomers are calculated to be -82.7 . -106.8 and $-100.6 \mathrm{Kcal} / \mathrm{mol}$. respectively in consistent with the experimental results. Energetic or kinetic factors may also result in different adsorption behaviors on Ag. Au. and $\mathrm{Cu}$. It has to be admitted that the computational model used is a complex between the cytosine and a single metal atom. which may not be adequate for the phenomenon under investigation concerns cỵtosine adsorbed to $\mathrm{Cu}$. Ag. and $\mathrm{Au}$ surfaces. We plan to choose a suitable multiple atom cluster with a consideration of the solvation effect in future. Our study shall be helpful to understand the interaction of pyrimidine bases and metals.

\section{Summary and Conclusions}

The SERS spectral evidence in silver. gold, and copper surfaces indicated that the population of cytosine tautomers should be different depending on metal surfaces and substrate conditions. Our DFT calculations indicated that the energetic difference of the tautomers on gold should be different than those on silver or copper as well as those in the gas phase. On $\mathrm{Ag}$ and $\mathrm{Cu}$, the $\mathrm{N}_{1}$-coordinated zwitter ionic form was found to be the most stable. The metal-N bond distance was calculated to be shorter for $\mathrm{Au}$ and $\mathrm{Cu}$ than $\mathrm{Ag}$. This should result in the lower desorption temperature of cytosine on $\mathrm{Ag}$ than on $\mathrm{Au}$ or $\mathrm{Cu}$.

Acknowledgment. This work was supported by the Soongsil University research fund. S.W.J would like to thank Dr. Jong Kuk Lim, Prof. Jaebum Choo and Prof. Kwan Kim on SERS studies.

\section{References}

1. Witmer, M. R.; Falcomer, C. M: Weiner, M. P.: Kav, M. S: Begley, T. P.: Ganem, B.: Scheraga, H. A. Kucleic Acids Research 1991. 19. 1

2. Pergolese. B.: Bonitacio. A.: Bigotto. A. PhnsChenChenthws. 2005. 7.3610

3. Sinden, R. R. DNA Stucture and Function Academic Press: San Diego. 1994.

4. Thibault, G.: Tsitrin, Y.: Davidson, T: Gribun. A.: Houry, W. A. The EMBO Joumal 2006. 25. 3367.

5. Person. W. B.: Spaczepaniak. K. Calculated and Experimental librational Spectra and Fone Fields for Lolated Pyrimidine Bases in ribrational Spectra and Structure: During. J. R., Ed: Dekker: New York, 1992: Vol. 20.p 239.

6. Park. Y. C. Lee, J. S. Bull. Korean Chem. Soc, 2007, 28, 386.

7. Civeir. P. U. J. MOI. Struct. 2000. 532. 157.

8. Chandra. A. K: Michalska. D.: Wysokinski. R.: ZeegersHuyskens. T. J. Phws Chem. A 2004. 108. 9593.

9. Kumar. A.: Mishra P. C.: Suhai, S. J. Phys. Chem. A 2006, 110. 7719.

10. Santamaria, R.: Charro, E.: Zacarias. A.: Castro. M. J. Computational Chent 1999.20.511.

11. Wang. Y: Du. X.: Miao. W.: Liang. Y. J. Phws. Chem. B 2006. 110.4914

12. Ostblom, M.: Liedberg. B.; Demers, L. M.: Mirkin, C. A. J. Phus. Chem. B 2005. 109. 15150 .

13. Petronth, D. Y:: Kimura-Suda, H: Whitman, L. J:- Tarlov, M. J. J. Am. Chem. Soc. 2003. 125. 5219.

14. Demers. L. M.: Ostblom. M.: Zhang. H.: Tang. N.-H.: Liedberg. B.: Mirkin. C. A. J. Ant Chem. Soc. 2002. 124. 11248.

15. Yamada. T.: Shirasaka, K.; Takano, A,; Kawai, M. Surf. Sci. 2004. 561. 233.

16. Sanchez-Cortes, S.; Garcia-Ramos, J. V. Lamgmir 2002, 16, 764.

17. Kreibig. U.: Volmer. M. Optical Properties of Metal Clasters: Springer: Berlin. 1995.

18. Mulvaney. P. Lamgnuir 1996. 12.788.

19. Vo-Dinh. T. Bionedical Photonics Handbook: CRC Press: New York. 2003

20. Moskovits, M. Rev Hod. Plys. 1985. 57.783.

21. Joo. S. W. Bull Korean Chem. Soc. 2007. 28 . 1405. 
22. Cao. Y.: Jin. R.: Mirkin. C. A. Science 2002. 297. 1536.

23. Sellers. H.: Ulman. A.: Shnidman. Y.: Eilers. J. E. J. Am. Chem. Soc. 1993. 115.9389.

24. Ulman, A. Chem. Rew 1996,96.1533.

25. Bae, S. J. Lee. C.-R: Choi. I. S.: Hwang. C. S.: Gong. M.-S.: Kim. K.: Joo. S. W. J. Phys. (them. B 2002, 106.7076.

26. Joo. S. W. Chung. T. D.: Jann. W. Gong. M.-S.: Geum. N.: Kim. K. Langmair 2002. 18.8813

27. Joo. S.-W. Kim. Y. S. Col Sinf A 2004. 234. 117.

28. Cho, K.-H.: Choo. J. Joo, S.W. Specrochim Acta A 2005. 61 . 1141.

29. Cho, K.-H.: Choo, J. Joo, S.W. J. Mol. Struct 2005, 738.9

30. Lee. P. C.: Meisel. D. J. Phus Chem 1982. 86. 3391.

31. Creighton. J. A.: Alvarez. M. S.: Weitz. D. A.: Garofti. S.: Kim. M. W. J. Phws. Chent 1983. 87. 4793

32. Gaussian 03, Revision A.1; Frisch. M. I.: Trucks. G. W.: Schlegel, H. B.: Seuseria, G. E.: Robb, M. A.: Cheeseman, I. R:
Zakrzewski. V. G.: Montgomery. I. A. Jr.. Stratmantı. R. E.: Burant. J. C.: Dapprich. S.: Millam. J. M.: Daniels. A. D.: Kudin. K. N.: Strain. M. C.: Farkas. O.: Tomasi. T.: Barone. V.: Cossi. M.: Cammi. R.: Mennueci. B.: Pomelli, C: Adamo, C.: Clifford, S.; Oehterski, J.: Petersson. G. A.; Avala, P. Y: Cui. Q:- Morokuma. K.: Malick, D. K.: Rabuck. A. D.: Raghavachari. K.: Foresman. J B.: Cioslowski. T.: Ortiz. I. V.: Baboul. A. G.: Stefanow. B. B.: Liu. G.: Liashenko. A.: Piskorz. P.: Komaromi. I.: Gomperts. R.: Martin. R. L.: Fox. D. J.: Keith. T.: Al-Laham. M. A.: Peng. C. Y.: Nanayakkara, A.; Challacombe, M.; Gill. P. M. W.; Johnson. B.; Chen. W.: Wong. M. W. Andres. J. L.: Gonzalez, C.: HeadGordon. M:; Replogle, E. S:; Pople. J. A. Gaussian. Ine:; Pittsburgh. PA. 2003.

33. Kim. S.: Ihm. K.: Kang. T.-H.: Hwang. S.: Too. S.-W. Sinf Interf. Anal. 2005. 37. 294.

34. Les. A.: Adamowicz, L: Nowak, M. J.; Lapinski, L. Spectrochim. ActaA 1992, 48,1385 